\title{
The Effect of In-Game Advertising in SNS on Brand Equity
}

\author{
Jianhua Yang, Meizhen Zhang, Zhiqin Zou \\ Department of Marketing, Management School, Jinan University, Guangzhou, China \\ Email: jianh2003@163.com \\ Received 12 January 2015; accepted 13 February 2015; published 16 February 2015 \\ Copyright (C) 2015 by authors and Scientific Research Publishing Inc. \\ This work is licensed under the Creative Commons Attribution International License (CC BY). \\ http://creativecommons.org/licenses/by/4.0/ \\ c) (i) Open Access
}

\begin{abstract}
In recent years the boom of SNS has bestowed in-game advertising in SNS with great attention from media and the public. This paper explores how IGA in SNS affects brand equity, and how brand familiarity moderates the relationship between IGA in SNS and brand equity. The results indicate that: 1) IGA in SNS has positive effects on brand awareness, brand association and perceived quality. However, such effect on brand loyalty is not significant. 2) Brand familiarity negatively moderates the effect of IGA in SNS on brand awareness, perceived quality and brand association while the effect on brand loyalty is not significant.
\end{abstract}

\section{Keywords}

SNS, In-Game Advertising, Brand Equity, Brand Familiarity

\section{Introduction}

Brand equity can enhance consumers' willingness to pay a premium, reduce consumers’ price sensitivity as well as reducing the effect of brand in the competitive marketing activities and the marketing crisis. Therefore, how to construct and manage brand equity has become an issue of vital importance for both marketers and policymakers. Attached to brand, brand equity has a relationship with consumer. This can bring extra income for the enterprise in the future [1]. In order to promote brand equity, many enterprises have done a lot of advertising. Brands with huge advertising budget always have a better performance in brand equity [2]. However, consumers have some boycott attitudes toward advertising; excessive repetitive advertising can cause consumers disgust. Instead, implantable advertising is not easy to have a negative impact on brand evaluation when enhancing the product purchase rate.

SNS has witnessed its most prosperous stage due to the rapid development of Web 2.0. The popularity of SNS should attribute to game components; it not only strengthens the user viscosity and also expands the size of so- 
cial network. The application model of “Game components + SNS” has been widely accepted and approved. This study discusses from two aspects. First, according to the former [3], we examine the effect of the in-game advertising (IGA) in SNS on brand equity dimensions respectively; second, we investigate how the brand familiarity adjusts the relationship between IGA in SNS and brand equity.

\section{Literature Review and Hypotheses}

\subsection{Social Networking Service (SNS)}

SNS is based on the theory of "six degrees of separation". "Six degrees of separation" means that, in the interpersonal context, among the most as long as through six friends you can make friends with any strangers. Social networking service is based on "Six degrees of separation" to provide the user a communication web site platform. Everyone is a social network "nodes”, and developed in continuous contact with the various links; belong to different forms and rules of relationships ring [4]. Users can through existing friends connection make new friends, to expand their circle of friends on social network platform.

By increasing user groups and building personal relationships, SNS let users play games and other entertainment, and can also make new friends, expand communication circle. At present, SNS in the domestic are mainly Renren, Kaixin, Qfriend, Myspace, 51.com, et al. The most popular among them is Renren and Kaixin, and they mainly get favor from target users through the game and application plug-ins of entertainment services.

SNS website with high popularity can create high commercial value. For advertisers, mainly reflected in: first, users will rely on SNS to get abundant resources and information, this dependence can translate into the loyalty of SNS platform; second, the SNS website is more interactive, relying on network real-time interactive features [5]. Both SNS network advertising and interpersonal communication can be real-time interactive; third, users belonging to different social circles, there is the inherent characteristics of a particular social circle. So it is easier for enterprise to lock precise target market or target customers; fourth, in SNS platform, marketing modes such as precision marketing, word of mouth marketing and product placement marketing, can be combined to form a more accurate and more efficient promotion effect.

\subsection{In-Game Advertising}

IGA refers to strategically get the specific brand information and even virtual entity into the game. IGA subtly increases chance to contact with product allowing players in the game state, thus to achieve brand promotion purposes. IGA, compared with the traditional advertising and other implantable advertising media, has three characteristics:

First of all, IGA can subtly delivery the advertising message. Compared with traditional advertising, IGA can be cleverly integrated advertising message into the carrier context. When in a more relaxed state, the audience can be persuaded by advertising through the edge of the path, rather than the center of the path. It is possible in a natural and enjoyable way to enable consumers to accept advertising messages [6]. Huang and Yang [7] said that, when the game is less related to advertising, the player is easier to identify advertising; conversely, the player is easier to accept the advertising. Because information of advertising has become a part of the game. Therefore, advertising information will be subtly conveyed to the users along with the progress of game.

Second, IGA has repeatability. Compared with traditional advertising, there is no time and space limitation in IGA. Film and television and other traditional media are generally for one-time propagation, audience has less chance to re-view. While the game to users by high viscosity, IGA can naturally pass information to the user.

Third, IGA has the interactive entertainment. With a strong interactive, game can enhance the player's sense of belonging and identity of brand. When user interaction in the game, will produce various types of emotions and feel different experiences, and these will directly or indirectly influence the evaluation of brand [8]. That is, IGA will affect the evaluation on the brand of players.

IGA of SNS with game characters, scenes, props, plot, et al. combined closely, hidden behind the game, which bring the new profit pattern for SNS. And, many studies show that well-designed game on social networking sites can increase user viscosity and the will continue to use the SNS site [9]. For example, in December 2008, Buick Regal appeared at "parking wars" in the "Kaixin"; and in recent years, "Yuehuo" juice of COFCO also with "Happy Farm” carried out promotional activities. 


\subsection{Affect of IGA in SNS on Brand Equity}

The earliest concept of brand equity via advertising, they increasingly get marketing academia extensive attention. Prior research defines brand equity on the basis of the relationship model between brand and consumer. This model argues that the brand equity should study from the perspective of consumers, and surround consumer to establish brand connotation [3]. That is, the brand equity mainly emphasis the perception of consumer on brand and behavior generated from these perceptual [3].

Aaker defines the four composition dimensions of brand equity as brand awareness, brand association, perceived quality and brand loyalty [10]. For a further, building brand equity concept model, Yoo et al. measured brand awareness, brand association, perceived quality and brand loyalty to estimate brand equity [11]. Reference on Aaker, we define brand asset with four dimensions: brand awareness, brand association, perceived quality and brand loyalty.

Brand awareness is the ability to consumers or potential consumers to realize relationships between a certain brand and certain products or services. In some situations, especially in low investment decision-making process, when brand awareness of consumer is higher, brand preference is higher. In other words, customers tend to choose their more familiar brand. And IGA can enhance consumer's brand awareness. According to Nelson, "for the first time to play games or have played more than once, player can easily recall the game's brand in the short or long term” [12]. With memory deepening, brand awareness will influence consumers' decision. Thus:

H1a: IGA in SNS has a positive effect on brand awareness.

Brand association reflects the cognition, attitude and emotion of consumers to brand. Consumers have different association to different brands; they will consciously or unconsciously compare the differences between brands. IGA can cause the player to products association and subtly enhance the promotion effect of brand. IGA in SNS can directly affect the degree of brand association, as consumers unconsciously accept IGA, so it is easy for players to contact experience and feelings gained from game with brand. Therefore, when the audience has association on game, they will also have association on brand, so the goal of advertising communication can be achieved. So we get the following assumptions:

H1b: IGA in SNS has a positive effect on brand association.

Perceived quality is consumers' overall impression on quality of a brand [3] [10], this kind of impression is often subjective. Even if consumers are not exposed to the real products or services, they can also be subjective to judge the quality of the product or service. When consumers feel good even emotional love for the game, IGA have a positive impact on perceived quality; otherwise, the perception of brand quality will be destroyed. Therefore, we propose the third hypothesis:

H1c: IGA in SNS have a positive influence on perceived quality.

Brand loyalty is that consumers contact with the brand in the long-term to produce a preference psychology, and this positive emotion can motivate consumers to buy the product or service of the brand in the long-term. And positive feelings of consumers will be associated with the brand information of IGA in SNS, so consumers will be more faithful to the brand of IGA. Therefore, the fourth hypothesis is proposed:

H1d: IGA in SNS has a positive effect on brand loyalty.

\subsection{The Moderating Role of Brand Familiarity}

Brand familiarity refers to the experience of consumer accumulated related to the product or service, including direct and indirect experience, such as exposure to advertising, sales staff to interact, et al. When the brand familiarity is not the same, advertising information also play a different role. Research has shown that when subjects saw unfamiliar brand advertising, they were more likely to be motivated to learn and form an accurate impression of the brand. On the contrary, if you are familiar with the brand advertising present, they have more to enhance the cognitive and make confirm the information processing. That is, when consumers are very familiar with brand, brand acknowledge has been the initial formed, so that the original brand awareness and attitude is not very susceptible to advertising and other factors.

Brand familiarity is the degree of understanding about the brand accumulated in the consumers' memory after contacting and experience the brand. That is, the more contact with brand, the higher brand familiarity [3]. When consumers have the high brand familiarity, the original brand awareness can interfere with the role of IGA, lead to the brand attitude will almost not change; instead, when consumers' brand familiarity is low, their brand attitude will change because of IGA. Thus: 
H2: brand familiarity negatively moderates the effect on IGA in SNS to brand equity.

H2a: brand familiarity negatively moderates the effect on IGA in SNS to brand awareness.

H2b: brand familiarity negatively moderates the effect on IGA in SNS to brand association.

H2c: brand familiarity negatively moderates the effect on IGA in SNS to perceived quality.

H2d: brand familiarity negatively moderates the effect on IGA in SNS to brand loyalty.

In this study, according to Keller [3], brand awareness, brand association, perceived quality and brand loyalty are as the four dimensions of brand equity. IGA in SNS is an experimental stimuli, and brand familiarity is a moderator variable, we explored how IGA in SNS affects brand equity.

\section{Methods}

\subsection{Stimuli}

If the participant is more to come into contact with IGA, we cannot judge results of experiment coming from the success of the experiment operation or a raise of advertising repetition. In addition, due to the preference of brand consumers may have high brand familiarity. Then, if the consumer preference of brand is high, it will interfere the moderating of brand familiarity. Therefore, we through a pre-test pick the games, advertising and brand in SNS before the formal experiment. In the pre-test, we select six different SNS sites and pick a game with advertising from each site. 30 (male 16, female 14) graduate students in a comprehensive university are investigated. Experimenter guides the 30 participants to land the game of selected SNS sites and fill in the questionnaire at the end of the game. Questionnaire is mainly for: "whether played the game before", "whether come into contact with advertising in the game", et al.

According to the questionnaire we pick SNS sites and its game. The restaurant game of "Layis" is $100 \%$ on "have not played before" and "the game of advertising is not in contact before" from the questionnaires and it can meet the requirements of the experiment. Therefore, we decide the restaurant game and "Layis" as the stimulus.

\subsection{Participants and Procedure}

135 undergraduate and graduate students ( $51 \%$ for woman, $49 \%$ for man) participate this study and they are randomly assigned to three experimental groups with 45 people respectively. They are 19 to 27 years old. We recycle 132 questionnaires from the experiment, getting rid of invalid questionnaires, we get 126 effective questionnaires. Three experimental groups have equal number of valid questionnaires and the effective questionnaire recovery rate is $95.4 \%$.

The study survey method is to compare the experimental group and control group and can be divided into two experiment groups and a control group. In the experimental group A1 participants play a game without product placement on SNS; in the experimental group A2 participants play the same game with product placement on the same SNS; in the control group A3 there is not any game and any ads presented to participants. The specific process of experimental operation is as follows:

First of all, 135 participants are randomly assigned to three groups on average, to ensure that every participant will only accept one set of experiments. Participants are asked to read the guide on the first page of experiment materials. Then participants independently login game and fill in the questionnaire accordance the requirements. Participants of A1 login Qfriend and played QQ restaurants game (no advertising). Participants of A2 login Renren and played Renren restaurant game ("Layis" ads); there is no website, no game and no advertising in A3, they only have been told to an advertising experiments. At the end of the study, three groups of participants complete the scale on four dimensions of brand equity and demographic measures (e.g., gender, age).

The questionnaire is based on previous developed scale of brand equity. Each dimension of brand equity has three indicators: the scale of brand awareness and perceived quality is from Keller [10] and Yoo [11]; the scale of brand loyalty and brand association is from Yoo [11] and Netemeyer [13]. We use a five-point Likert scale. (1 represents strongly disagree, 5 represent strongly agree)

The moderating of brand familiarity is measured through three average of multi-item "I am familiar with the brand", "I know the brand" and "I have heard of the brand". This also use a five-point Likert scale, the mean less than 3 regard as low brand familiar, while above 3 regard as high brand familiar. 


\section{Results and Analysis}

\subsection{Reliability and Validity}

We use the internal consistency coefficient (Cronbach's $\alpha$ ) to test samples for reliability. As shown in Table 1, we can see that the sample indexes have good internal consistency $(\alpha>0.8)$. In the exploratory factor analysis, we use principal components analysis and select the maximum variance orthogonal rotation method to analysis sample data, the data is suitable for factor analysis $\left(\mathrm{KMO}=0.920, x^{2}=2597.205, p=0.000\right.$ ). The standardized load of 12 indexes on four factors factor are between 0.735 and 0.899 , and pass significance testing. From the above analysis, this study has high construct validity.

\subsection{Hypothesis Test}

We analyze respectively the effect of IGA in SNS on brand awareness, brand loyalty, perceived quality and brand association (one-way ANOVA).

The analysis results show as Table 2 and Table 3, A1 with no ads compared A2 with ads, we find the latter has a higher brand awareness than the former $\left(\mathrm{M}_{\mathrm{A} 2}=4.762, \mathrm{SD}=0.410\right.$, vs. $\mathrm{M}_{\mathrm{A} 1}=3.076, \mathrm{SD}=0.601 ; \mathrm{F}(1,82)$ $=225.547, p<0.05$ ). From Table 4 and Table 5, both A1 and A3 show relatively low brand awareness, so it indicate that brand awareness has not significant difference for whether played the game $\left(\mathrm{M}_{\mathrm{A1}}=3.076\right.$, $\mathrm{SD}=$ 0.601 , vs. $\left.\mathrm{M}_{\mathrm{A} 3}=3.076, \mathrm{SD}=0.657 ; \mathrm{F}(1,82)=0.000, p=0.986>0.05\right)$. So, IGA in SNS has a significant influence on brand awareness, H1a is proved.

We can see from Table 6 and Table 7, brand association with IGA is significantly higher than that without IGA $\left(\mathrm{M}_{\mathrm{A} 1}=3.03, \mathrm{SD}=0.730\right.$, vs. $\left.\mathrm{M}_{\mathrm{A} 2}=4.68, \mathrm{SD}=0.405 ; \mathrm{F}(1,82)=164.680, p=0.000<0.05\right)$, which means consumers can have stronger on brand association through IGA in SNS. H1b is proved.

Table 1. Reliability and validity analysis.

\begin{tabular}{cccc}
\hline Variable & Item & Factor Loading & Cronbach’s $\alpha$ \\
\hline \multirow{2}{*}{ Brand Awareness } & Bc1 & 0.876 & 0.831 \\
& Bc2 & 0.753 & \\
Brand Association & Bc3 & 0.863 & 0.845 \\
& Ba1 & 0.847 & 0.866 \\
Perceived Quality & Ba2 & 0.785 & 0.886 \\
& Ba3 & 0.899 & 0.814 \\
\hline
\end{tabular}

Table 2. The descriptive of brand awareness.

\begin{tabular}{ccccccccc}
\hline \multirow{2}{*}{$\begin{array}{c}\text { Brand } \\
\text { Awareness }\end{array}$} & $\mathrm{N}$ & Mean & Std. Deviation & Std. Error & \multicolumn{2}{c}{ 95\% Confidence Interval for Mean } & Minimum & Maximum \\
\cline { 7 - 8 } & & & & & Lower Bound & Upper Bound & & \\
A1 & 42 & 3.076 & 0.6007 & 0.0927 & 2.889 & 3.263 & 1.7 & 4.0 \\
A2 & 42 & 4.762 & 0.4102 & 0.0633 & 4.634 & 4.890 & 3.7 & 5.0 \\
Total & 84 & 3.919 & 0.9901 & 0.1080 & 3.704 & 4.134 & 1.7 & 5.0 \\
\hline
\end{tabular}

Table 3. The ANOVA of brand awareness.

\begin{tabular}{ccccc}
\hline Brand Awareness & Sum of Squares & df & Mean Square & F \\
\hline Between Group & 59.674 & 1 & 59.674 & 225.547 \\
Within Group & 21.695 & 82 & 0.265 & 0.000 \\
Total & 81.370 & 83 & & \\
\hline
\end{tabular}


Table 4. The descriptive of brand awareness.

\begin{tabular}{|c|c|c|c|c|c|c|c|c|}
\hline \multirow{2}{*}{ Brand Awareness } & \multirow{2}{*}{$\mathrm{N}$} & \multirow{2}{*}{ Mean } & \multirow{2}{*}{ Std. Deviation } & \multirow{2}{*}{ Std. Error } & \multicolumn{2}{|c|}{ 95\% Confidence Interval for Mean } & \multirow{2}{*}{ Minimum } & \multirow{2}{*}{ Maximum } \\
\hline & & & & & Lower Bound & Upper Bound & & \\
\hline A1 & 42 & 3.076 & 0.6007 & 0.0927 & 2.889 & 3.263 & 1.7 & 4.0 \\
\hline A3 & 42 & 3.074 & 0.6571 & 0.1014 & 2.869 & 3.279 & 1.7 & 4.0 \\
\hline Total & 84 & 3.075 & 0.6257 & 0.0683 & 2.939 & 3.211 & 1.7 & 4.0 \\
\hline
\end{tabular}

Table 5. The ANOVA of brand awareness.

\begin{tabular}{cccccc}
\hline Brand Awareness & Sum of Squares & df & Mean Square & F & Sig. \\
\hline Between Group & 0.000 & 1 & 0.000 & 0.000 & 0.986 \\
Within Group & 32.497 & 82 & 0.396 & & \\
Total & 32.497 & 83 & & & \\
\hline
\end{tabular}

Table 6. The descriptive of brand association.

\begin{tabular}{ccccccccc}
\hline $\begin{array}{c}\text { Brand } \\
\text { Association }\end{array}$ & $\mathrm{N}$ & Mean & Std. Deviation & Std. Error & \multicolumn{2}{c}{ 95\% Confidence Interval for Mean } & Minimum & Maximum \\
\hline A1 & 42 & 3.03 & 0.730 & 0.113 & 2.80 & 3.26 & 2 & 4.0 \\
A2 & 42 & 4.68 & 0.405 & 0.062 & 4.55 & 4.81 & 4 & 5.0 \\
Total & 84 & 3.85 & 1.017 & 0.111 & 3.63 & 4.08 & 2 & 5.0 \\
\hline
\end{tabular}

Table 7. The ANOVA of brand association.

\begin{tabular}{ccccc}
\hline Brand Association & Sum of Squares & df & Mean Square & F \\
\hline Between Group & 57.338 & 1 & 57.338 & 0.000 \\
Within Group & 28.550 & 82 & 0.348 & 164.680 \\
Total & 85.888 & 83 & & \\
\hline
\end{tabular}

IGA in SNS has a main effect on perceived quality. For two groups not accept advertising information, regardless of playing games on SNS, their perceived quality do not show significant difference $\left(\mathrm{M}_{\mathrm{A} 1}=2.481\right.$, SD $=2.481$, vs. $\mathrm{M}_{\mathrm{A} 3}=2.648$, $\left.\mathrm{SD}=0.726 ; \mathrm{F}(1.82)=1.76, p=0.188>0.05\right)$. Compared with without IGA, the group with IGA shows a higher perceived quality of brand $\left(\mathrm{M}_{\mathrm{A} 1}=2.481, \mathrm{SD}=2.481\right.$, vs. $\mathrm{M}_{\mathrm{A} 2}=4.695$, $\mathrm{SD}=$ 0.563; $\mathrm{F}(1.82)=344.83, p<0.05)$. That is, the reason of improved perceived quality is IGA rather than the game itself. In-game advertising on perceived quality of brand has a significant positive influence, H1c is supported.

And in terms of brand loyalty, there is no significant difference between two experiment groups $\left(\mathrm{M}_{\mathrm{A} 1}=1.85\right.$, $\mathrm{SD}=0.388$, vs. $\left.\mathrm{M}_{\mathrm{A} 2}=1.86, \mathrm{SD}=0.392 ; \mathrm{F}(1,82)=3.871, p=0.053>0.05\right)$, so H1d is not supported.

The result shows that for the IGA brand familiarity has a moderating effect on brand awareness, brand association, and perceived quality of consumer, but this effect is not significant for brand loyalty.

Compared low brand familiarity with high brand familiarity, brand awareness of participants has a significant difference. Specially, the lower degree of brand familiar, the greater effect on brand awareness by IGA $\left(\mathrm{M}_{\text {low }}=\right.$ 4.733, $\mathrm{SD}=0.395$, vs. $\left.\mathrm{M}_{\text {high }}=3.717, \mathrm{SD}=0.444 ; \mathrm{F}(1,82)=61.115, p<0.05\right)$. H2a is proved.

From the result we can see IGA have a greater impact on brand association when participants have low brand familiarity (instead high brand familiarity) $\left(\mathrm{M}_{\text {low }}=4.68, \mathrm{SD}=0.377\right.$, vs. $\mathrm{M}_{\text {high }}=4.39, \mathrm{SD}=0.408 ; \mathrm{F}(1,82)=$ 5.626, $p<0.05$ ). Therefore we can believe that the brand familiarity have a significant moderating role to the effect on IGA of brand association, H2b is supported.

Participants with low brand familiarity compared to high brand familiarity, there is a significant difference of quality awareness. And the lower brand familiarity with participants, the greater affected perceived quality by the advertising $\left(\mathrm{M}_{\text {low }}=4.84, \mathrm{SD}=0.279\right.$, vs. $\left.\mathrm{M}_{\text {high }}=4.15, \mathrm{SD}=0.939 ; \mathrm{F}(1,82)=11.574, p<0.05\right)$. So H2c is supported. 
Lower brand familiarity compared with higher brand familiarity, the mean of brand loyalty increase $\left(\mathrm{M}_{\text {low }}=\right.$ 2.89, $\mathrm{SD}=0.215$, vs. $\left.\mathrm{M}_{\text {high }}=2.61, \mathrm{SD}=0.661\right)$, but it did not meet the significant level $(p=0.058)$. That is, brand familiarity did not significantly moderate the relationship between IGA on brand loyalty, H2d is not supported.

\section{General Discussion}

\subsection{Research Conclusion}

With empirical research, we discuss the effect of IGA in SNS on brand equity of brand awareness, brand association, perceived quality and brand loyalty, and the moderating role of brand familiarity. The result shows that:

First, IGA in SNS has significant positive influence on three dimensions of brand equity, like brand awareness, brand association, perceived quality. The more frequent consumers contact with the placement in the game, the easier to remember the IGA involved, thus brand awareness and brand association are easier to remember in the mind. And passed the positive content of advertising can increase the feeling of brand quality. However, IGA has no significant positive impact on brand loyalty. We argue that the reason is building brand loyalty is a very complex process and difficult to through one operation improve customer brand loyalty significantly.

Second, the brand familiarity can moderate the effect of IGA in SNS on brand awareness, brand association, perceived quality. The lower consumers to the brand familiarity, the more influence of ads in SNS; while the higher of brand familiarity, the less influence of ads in SNS by existing norms.

\subsection{Managerial Implications}

IGA in SNS is a chance to enhance the brand equity, especially for the less well-known brands. Ads combined with the game, can subtly spread the core appeal of the brand. The enterprise not only shorten the distance between brand with consumer in the fun, and also indirectly to differentiate with competitors. This can be a competitive advantage difficult to heat.

Therefore, skillfully implanted brand advertising to game in SNS, on the one hand is to bring the pleasure of brand experience to consumers and form positive word of mouth; on the other hand, enterprise can accurately pinpoint target customers, so as to promote enterprise core value transferring.

\section{Limitations and Future Research}

There are some shortcomings from several aspects, mainly as follows:

First of all, the participants may have inherent perception of web games. This study selected Renren and Qfriends as IGA in SNS and the majority of students are very familiar to the two platforms. Although the author exclude the possibility of contact with games and advertising before test, there may still have inherent perception on the game according to understanding of the social networking sites. We can consider using not familiar with social networking sites to the general population in future, and even virtual network brand, thus excluding existing views and cognition makes experimental data more accurate and effective.

Secondly, sample selection is relatively single. Participants from the university are mainly behalf of the young and highly educated people. While difference of demographic variables such as gender, age, behavior characteristics, will have an effect on the results of the study. Future research more widely sampling can make findings apply to the entire market.

Finally, we only use brand familiarity as the moderator variable. Future research could consider more significative factors, such as involvement, matching degree of game content and brand, even the interaction of moderator variables.

\section{Acknowledgements}

This study is funded with ministry of education, humanities and social science research project "mechanism of the impact of new media and traditional media advertising coordination on brand equity” (10YJA630183); and projects of enterprise development institute, Jinan University.

\section{References}

[1] Guo, X.L. and Wang, Y.G. (2013) Global Consumption Orientation and Global Brand Attitude of Consumer-The 
Main Effect, Moderating Effect and Sino-US Differences. Nankai Business Review, 4-16.

[2] Buil, I., De Chernatony, L. and Martínez, E. (2013) Examining the Role of Advertising and Sales Promotions in Brand Equity Creation. Journal of Business Research, 66, 115-122. http://dx.doi.org/10.1016/j.jbusres.2011.07.030

[3] Keller, L. (1993) Conceptualizing, Measuring, and Managing Customer-Based Brand Equity. Journal of Marketing, 57, 1-22. http://dx.doi.org/10.2307/1252054

[4] Chen, B. (2005) Compatibility of Relationship Marketing and China Relational Business Model—The Perspective of Social Network Theory. Beijing Technology and Business University (Social Sciences), 20, 66-71.

[5] Xu, L.L., Li, G.H. and Tao, Y.F. (2012) The Change of Interactive Media and Advertising Credit Building. Beijing Technology and Business University (Social Sciences), 27, 52-57.

[6] Xu, X.J. (2010) The Effect of Advertising Persuasion. Beijing Technology and Business University (Social Sciences), 25, 79-83.

[7] Huang, H. and Yang, K. (2012) The Effectiveness of In-Game Advertising: The Impacts of Ad Type and Game/Ad Relevance. International Journal of Electronic Business Management, 10, 61-72.

[8] Herrewijn, L. and Poels, K. (2013) Putting Brands into Play: How Game Difficulty and Player Experiences Influence the Effectiveness of In-Game Advertising. International Journal of Advertising, 32, 17-44. http://dx.doi.org/10.2501/IJA-32-1-017-044

[9] Chang, C. and Chin, C. (2011) Predicting the Usage Intention of Social Network Games: An Intrinsic-Extrinsic Motivation Theory Perspective. International Journal of Online Marketing, 1, 29-37. http://dx.doi.org/10.4018/ijom.2011070103

[10] Aaker, A. (1996) Building Strong Brands. The Free Press, New York.

[11] Yoo, B., Donthu, N. and Lee, S. (2000) An Examination of Selected Marketing Mix Elements and Brand Equity. Journal of the Academy of Marketing Science, 28, 195-211. http://dx.doi.org/10.1177/0092070300282002

[12] Nelson, R., Yaros, A. and Keum, H. (2006) Examining the Influence of Telepresence on Spectator and Player Processing of Real and Fictitious Brands in a Computer Game. Journal of Advertising, 35, 87-99. http://dx.doi.org/10.2753/JOA0091-3367350406

[13] Netemeyer, G., Krishnan, B. and Pullig, C. (2004) Developing and Validating Measures of Facets of Customer-Based Brand Equity. Journal of Business Research, 57, 209-224. http://dx.doi.org/10.1016/S0148-2963(01)00303-4 
Scientific Research Publishing (SCIRP) is one of the largest Open Access journal publishers. It is currently publishing more than 200 open access, online, peer-reviewed journals covering a wide range of academic disciplines. SCIRP serves the worldwide academic communities and contributes to the progress and application of science with its publication.

Other selected journals from SCIRP are listed as below. Submit your manuscript to us via either submit@scirp.org or Online Submission Portal.
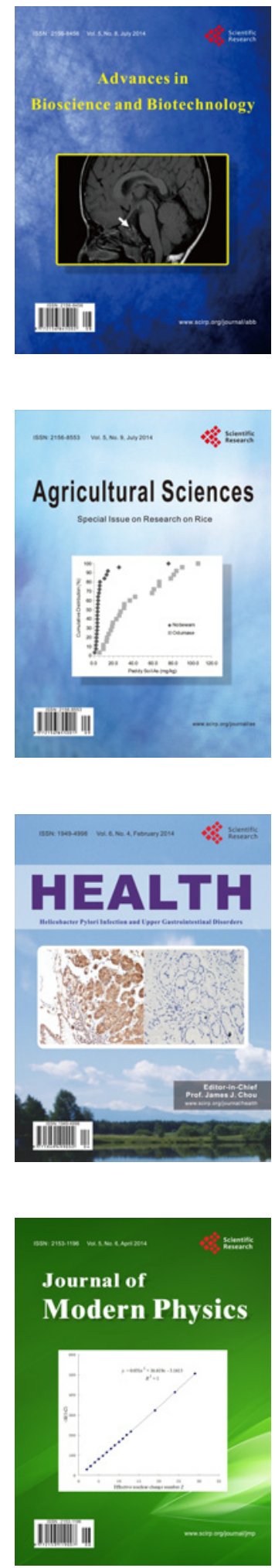
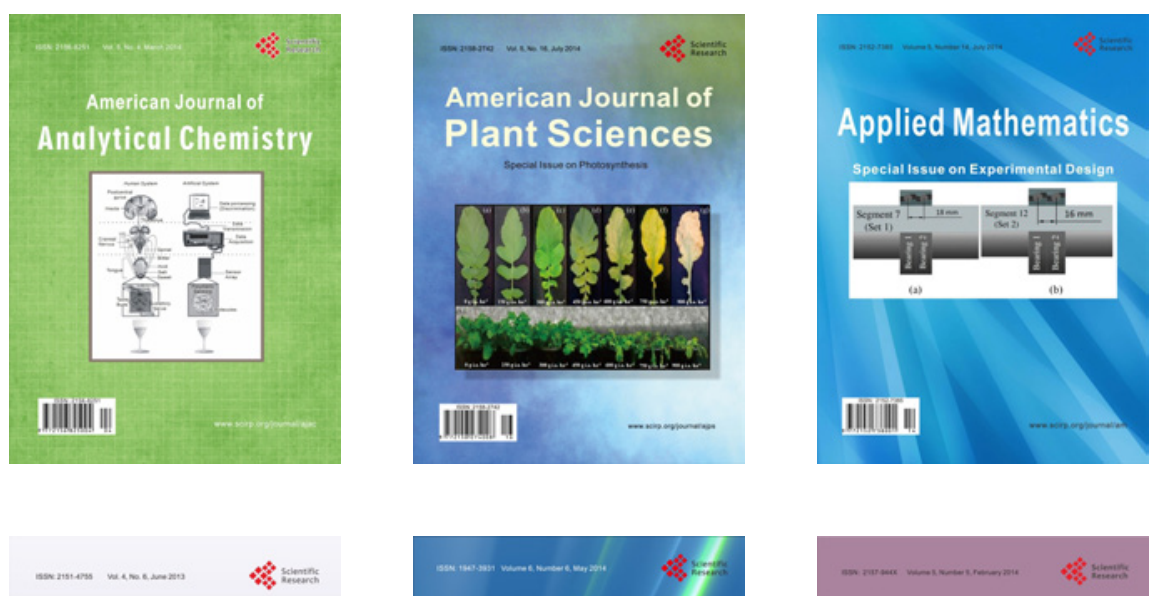

Creative Education
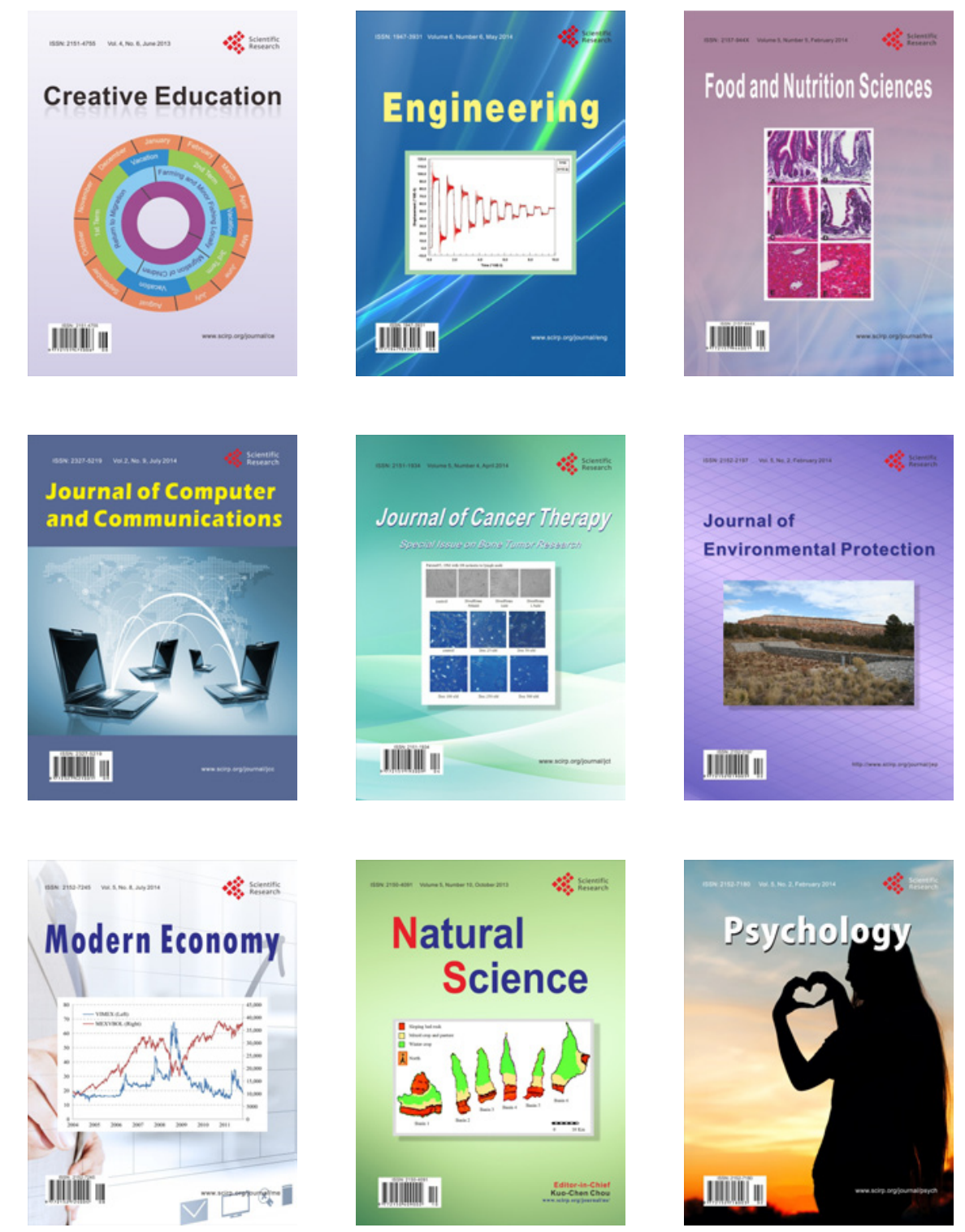